\title{
Episodes of Robotics and Manufacturing Automation Achievements from the Past Decades and Vision for the Next Decade
}

\author{
Geza Haidegger, Imre Paniti
}

Institute for Computer Science and Control (SZTAKI), Kende u. 13-17, H-1111 Budapest, Hungary

geza.haidegger@sztaki.hu,imre.paniti@sztaki.hu

\begin{abstract}
The past 3 decades are characterized by the introduction of digital tools in the manufacturing sector, and by the advent of mechatronics being used for repetitive and fast material handling within logistics. Retrospectively this time is referred as the $3^{\text {rd }}$ Industrial Revolution. Presently, the cyber-physical systems and cyber-physical production systems are being referenced as substituents of the $4^{\text {th }}$ Industrial Revolution. The Authors have selected some outstanding episodes within this transition time to highlight the Hungarian successful achievements developed and implemented by talented researchers and innovative ideas by far-looking professors. The article also offers elements of visions for technology development, focusing on the new results of robotics and on biotransformation in manufacturing.
\end{abstract}

Keywords: Technology Platforms; Strategic Research Agenda; Robotics

\section{Introduction}

The authors decided to select special, outstanding topics from the relevant time frame, from the time when technology enabled the introduction of digital mechatronic devices, controllers in the manufacturing sector, i.e. in the industrial environment, where goods and wealth are being generated. With such controllers simple mechanical devices, with one or two joints based robotic arms, 2-degrees of freedom, e.g. latch machines and early robotic pick \& place mechatronics were controlled and managed rather easily. By the application of digital MSI and LSI components based control-function with digital circuits; Hungarian scientists had achieved outstanding world-level success. By the special occasion of the present conference, celebrating the $70^{\text {th }}$ birthday of professor Imre Rudas, we can heartily congratulate to the pioneers of that time, and praise the professors and scientists that had given internationally approved reputation to Hungarian scientific results, while also supporting the strong educational background and teaching the next 
generation of scholars in robotics. There is only a small chance to mention all the outstanding events of those decades, so it is a personal selection of outstanding experiences of the authors that is to be mentioned below.

From our point of view, the final take-home message is not just a list of episodes of the past, but also to show the presently active open topics for scientists to solve. By the present process of re-electing the delegates to the European Parliament and the EU Commissions, the issues of how to manage the science and innovation at the EU-level is being debated. Presently, Europe, and in other continents of the world, the governments are pushing and forcing the digitalization of most sectors, like manufacturing, education, governance, etc. It is widely acknowledged that the fastest ROI (return-of-investment) will come from the manufacturing and logistics sector, and the social, educational changes probably need more time in this transition. The $4^{\text {th }}$ Industrial Revolution, sometimes called as re-industrialization points out the high relevance of ROBOTICS, and the need for raising robotics to significantly be a dominant contributor of modern production technology. The paper runs along the transition or evolutional path from the $3^{\text {rd }}$ towards the $4^{\text {th }}$ Industrial Revolution scenario, and dares to highlight some visionary views believed to become significant within the next couple of years.

\section{High Achievements at Selected Episodes of Success}

\subsection{Industrial Controllers Built from SSI and MSI, later on by LSI Circuit Elements}

Integrated semiconductor elements as coupling 10 to 50 transistors appeared on the shops that allowed logic gates and flip-flops to be implemented as low-level digital building blocks. Those small-scale integrated circuits were soon followed by higher-functional blocks, as registers, -for medium, and later on by 1000s of transistor-operated LSI-s, as arithmetic blocks, or microprocessor, memory arrays. In the middle of the 70thies, Small Scale-, Middle Scale- and Large Scale integrated semiconductor elements were widely used for a digital logic device as controllers. The special digital module from SSI and MSI building block elements to control 2 or more axes is named as hardware interpolator. NC machines had to be driven by such digital controllers. When LSI, i.e. microprocessors had entered the market, the NC machines got a controller with far more services and features, then managing, driving the axes. A real Hungarian success story is the development of the DIALOG CNC, several embedded microprocessor-based CNC (or RoC) capable of simultaneously driving 3 or even 5 axes featured mechatronics device. During the US Carter administration, this COCOM-breaker high-tech DIALOG CNC has outperformed Siemens and Fanuc controllers, and 
the US Congress had to admit, that high-tech Hungarian products could outperform American machines, and are being sold in the States.

\subsection{Bit-Slice-based Graphic Displays and Fast Control Systems with a Common Architectural Base}

CAD workstations and vector-graphic based displays were designed and integrated for standalone applications. Using the bit-slice computer-building semiconductor elements, extremely fast interpolators were designed, developed and produced suitable both for driving CNCs and also for driving graphic workstations.

\subsection{Developing Local Network-based Controllers}

The national industrial electronic companies and factories working in cooperation with university teams had achieved to come up with high-tech control devices. When machinery became more sophisticated, more complex and distributed, datenetworks were needed, and novel, Hungarian solutions were developed. Exceptional networked mechatronic devices were designed and implemented. One of the most outstanding results was the transporter of fuel-cells at the Hungarian Paks atomic power plant.

\subsection{High-Tech Data Networks Being Implemented as International Standard}

National experiences have shown the importance of being harmonized with international technical solutions. The research target was to get involved in international standardization. Due to the lack of key Hungarian individuals having personal contact at international standards fora, and experts, we should also get more and more involved in such technical groups. The development work on industrial networking had been with top-level COCOM regulations, but international standards' development has to be focused on at the ISO- and IEEE levels. General Motors automotive company's technical manager, Mike Kaminsky became the 'father' of the MAP standard, standing for Manufacturing Automation Protocol, the software element to connect factory shop-floor general equipment independently of vendor-specific interfaces. A philosophical dilemma ever since steers debates that deterministic networking protocol (token based or MasterSlave) is needed. or in contrast, stochastic protocol (e.g. TCP/IP) is adequate to operate data-networks on industrial shop-floors. Hungarian talented researcher, mathematician and philosopher, Ferenc Brody had given proof of a solution, by defining limitation for real-time and real-life applicability. Our Institute was the first partner from the Eastern Block to establish MAP Users Group to perform 
experiments and implementation of the MAP Standard's OSI-layers matching the international standard-protocol stack being developed and promoted for ISOapproval.

\subsection{Hungary as a New Member in the EUREKA Initiative's Family}

EUREKA is a European initiative to integrate national research activities between two or among several countries' selected partners. The focus was to eliminate parallel efforts and to teach participants on working together from different cultures, backgrounds and ecosystems. Hungary should join this group as the first country from the East. The authors were appointed to manage several such development and research projects related to factory-automation and robotics topics.

\subsection{Founding the ManuFuture Technology Platform}

The international EUREKA 'umbrella' team had given high-priority warning to the (EC's) EU's decision-making politicians, to counteract for saving the European manufacturing activities (firms, companies and product-designs \& productions) from leaving Europe for the Far-East.

In previous publications, [1] we have given details on manufacturing-related ETPs. Probably the largest ETP was given the name ManuFuture, pointing out the very high importance of maintaining and enhancing these manufacturing activities in Europe.

\subsection{The Tasks and Responsibilities of the ETP-s}

ETPs are industry-led technology-oriented fora as key participants (actors) in driving innovation, knowledge transfers for European successful competitiveness [2].

"ETPs develop vision paper(s), research and innovation agendas (SRAs) and roadmaps for actions at the EU and national level to be supported by both private and public funding. They mobilize stakeholders to deliver on agreed priorities and share information across the EU. ETPs are independent and self-financing entities. They conduct their activities in a transparent manner and are open to new members. The Tasks are:

Preparing and developing a VISION document, with a time-domain of 10 or 10+ years, so that the members of that Platform can share the same view for the future, explaining it in a harmonized, detailed view. 
Preparing, developing a Strategic Research and Innovation (SRA) Agenda; listing what are the missing knowledge and practice solutions building blocks, that are not yet ready, but need to be applied rather soon in order to reach the future environment vision by the end of the next 10 years.

Preparing, developing a ROADMAP, that has scenarios for possible best or worst estimates or most probable scenarios, by allocating financial support, manpower and infrastructure parameters together with the time-duration estimates.

ETPs are also responsible for establishing a close, industry - academia- and educational partnership, to have a balanced view from many different domains." $[2]$.

\subsection{ManuFuture ETP with National Support from Member States}

The European ManuFuture Technology Platform [3] has been responsible for the preparation of the Vision 2020 document, followed by the SRA in 2006, and finally deployed the ManuFuture Roadmap in 2013.

This work has given a good base for the EC offices to generate the Work program(s) for the Horizon 2020 and the $7^{\text {th }}$ Framework program.

Similarly, to other EU member-countries, National versions for Vision, for SRA and for Roadmap had been prepared, translated and distributed. In Hungary, the national TP on manufacturing was hosted by GTE, the Scientific Society for Mechanical Engineers [4]. All relevant documents and their translations on national reworked versions are available for download from www.gteportal.eu.

\subsection{MTA SZTAKI as Centre of Excellence in the EU Framework Programs}

From FP4 until FP8 Horizon2020, MTA SZTAKI has been a high winner of EU R\&D\&I projects. Key topics are ICT and Factory automation.

A special title, as "EU Centre of Excellence in Computer Science and Control" was donated by the EC. Industrial digitization projects and integration of related technologies has generated a trust with industrial end-users, e.g. with robotic laser-welding, implementing Digital Factory, Digital-TWIN solutions, Industry 4.0 Use-Cases, or Robotic sheet forming with cloud-application in digital factories [5]. 


\section{The Present Work of ManuFuture ETP}

The ManuFuture ETP has remained an active group of experts for the past 15 years. The first ROADMAP was deployed in 2008, after a consensus based Vision and SRA was harmonized and disseminated. In the organization chart you will see the following: the High Level Group, the Industrial Support Group, the Industrial Advisory Group, the Mirror Group for strengthening the ETP, and for establishing PPPs as EFFRA [6].

When the ManuFuture ETP was preparing its first Vision, SRA and Roadmap, -a full decade ago- the SRA has declared Competitiveness, Sustainability and High Added Value as Innovation and Research needs, with caring for environment and resource management. The Roadmap was explained based on Figure 1.

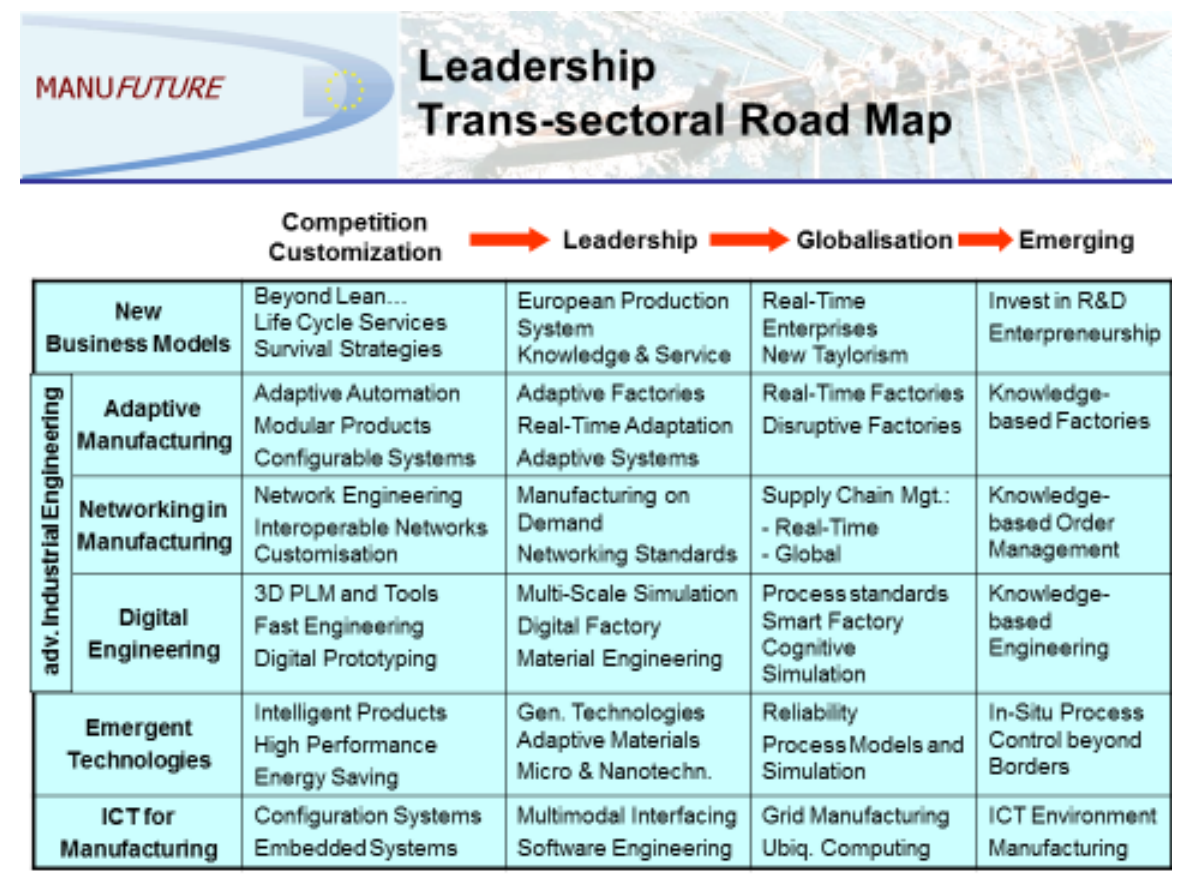

Figure 1

The structured ROADMAP of 2008 - CManuFuture

From 2016, a decision was accepted by the HLG group to go forward, and repeat the activities of the ManuFuture ETP starting with a vision paper for 2030. This harmonized version has been developed and is ready for distribution as a 'Consultation Version' ManuFuture Vision2030, while the SRIA for 2030 is also soon to be available. 
Even when the documents are freely available, there is a need to support the dissemination, and HLG members are requested to actively help getting the documents to reach the targeted readers, i.e. the decision-makers, and technologysupporters.

\subsection{Vision2030: The Structure with the Content}

The first chapter of the Vision2030 [7] shows the Manufacturing Industry Today, while Chapter 2 details the megatrends and drivers for manufacturing. Chapter 3 gives vision for scenarios and models for the future manufacturing processes. Vision and strategy are detailed in Chapter 4, and the Vision Building Blocks are described in Chapter 5. A short terminating chapter deals with Manufacturing \& Society relevancies in the vision. The document is a contribution to political, economic, ecologic, and social orientation from a European perspective.

\subsection{European Manufacturing - to Cope with Local and Global Challenges}

Manufacturing is the backbone of the European economy: with 2.1 million enterprises, employing 30 million workers. The decline in Europe of added value production is disturbing, thus priority must be given to manufacturing.

Competition and cooperation both increase at a global level, and thus the complete manufacturing innovation ecosystem needs to be involved for a change.

Today, society and world economies are undergoing major changes, driving a social transformation as important as the first industrial revolution. These changes are a global phenomenon, affecting the way we live, work and behave. An unprecedented increase in the speed of development in science and technology, fast diffusion of knowledge, the scarcity of resources and a new generation of consumers will pose challenges and opportunities for manufacturing. We are facing a shift in the paradigms for global productions and services.

Figures 2. Highlight the trends and drivers foreseen for the future of European Manufacturing: 


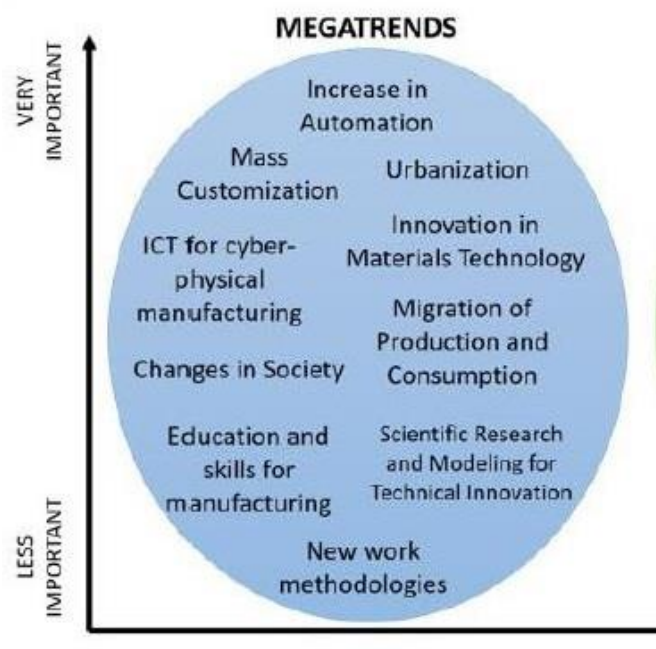

CERTAIN

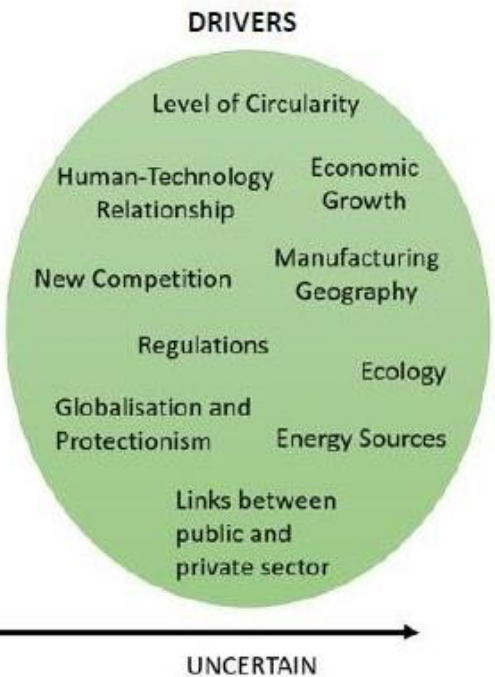

UNCERTAIN

Figure 2

Megatrends and drivers by importance and certainty. (ManuFuture

\subsection{Models of Future Manufacturing Scenarios}

European manufacturing will have to evolve to exceed the customer's expectations in design, quality, and service, and become even more flexible and adaptable. It must be user-centric; the customers will have a central role in value creation. Bionic manufacturing will enhance and augment relevant human capabilities. Nature-inspired manufacturing can lead to new frontiers. Circular economy is a large collaborative endeavor and manufacturing is at its core. Education and lifelong learning will become a critical function, and the new concept of learning factories will offer new challenges.

MANUFUTURE ETP had a Vision with 4 scenario models for the development of value networks and manufacturing systems (see Fig. 3)

*Globally Integrated Value Networks; *Regional Value Creation for Global Markets; *Regional Value Creation for Regional Markets; *Regionally Regulated Virtual Value Networks.

The entities in the Economy (factories, companies, SMEs, etc.) will probably integrate these to respond to requirements of the market, of the products, and of resource-availabilities. 


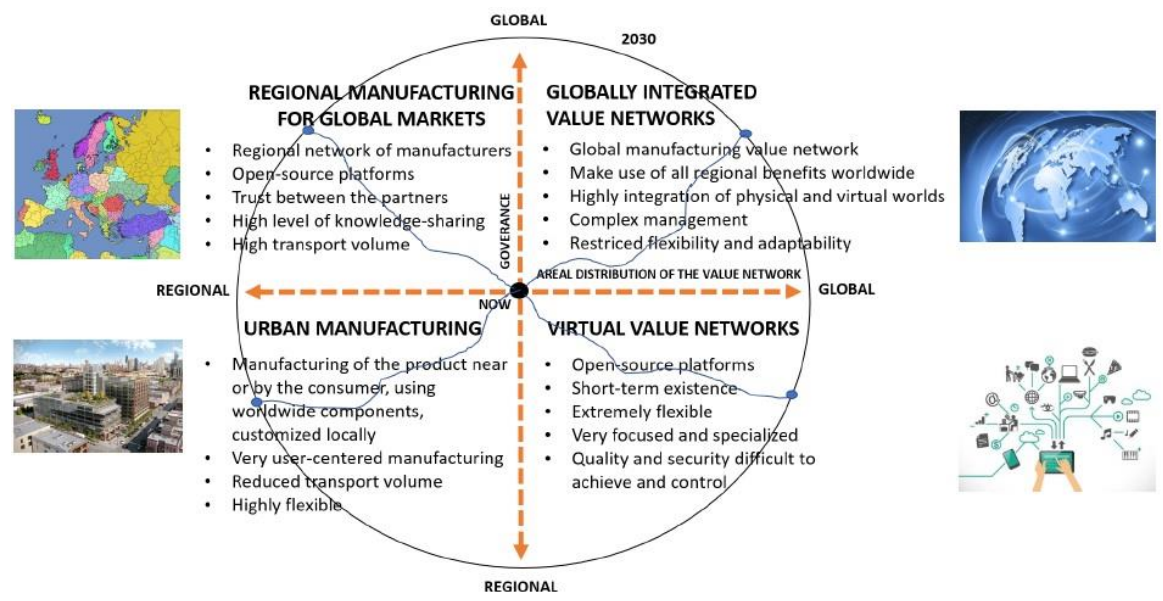

Figure 3

Scenarios for future manufacturing @ManuFuture

\section{Preparing the Strategic Research and Innovation Agenda (SRIA)}

The HLG of ManuFuture is in the process of collecting the technologies in need to develop solutions for the realization of the vision mentioned in the VISION2030 documents. The working list is requested to be broadened and extended as further inputs are given and collected Europe-wide. The integration of suggested SRIA elements are being edited in the HLG by Luís Carneiro, from INESC TEC. [8]

Declared R\&D\&I priorities are:

- Manufacturing technology and processes;

- Digital transformation;

- Robotics and flexible automation;

- Nano-technology and new materials;

- Biological transformation of products, processes and value creation;

- Customer driven manufacturing;

- Human Centered Manufacturing;

- Agile manufacturing systems design and management;

- Circular economy, resource and energy efficiency;

- New business logics and models. 
Other ETPs and also national TP-s are invited to share and harmonize these lists. We have information regarding the German National Platform, that their version has already reached a version classified as ARBRIDGED level for SRIA, by the consortium led by Stuttgart IPA. [9].

According to the Strategic Research Agenda (SRA) for Robotics in Europe two trends will demonstrate the impact of robotics technology and the importance of investments:

1) "Technologies traditionally associated with the service robotics sector will migrate into industrial automation yielding smarter robots and open up new markets."

2) "The maturing of navigation, localization, sensing and motion control technologies will enable economically viable service applications."

However, SRIA from both the ManuFuture and other ETPs, like BigData Value Association (GBVA), euRobotics, etc., jointly declare, that AI: Artificial Intelligence technology research will dominate future achievements globally.

The vision and plan is to generate, create a connected EU-wide Artificial Intelligence Ecosystem. The national governments are suggested to give high priority to support local and regional, furthermore EU-wide R\&D\&I actions to give a European boost for AI-based research results.

\subsection{Robotics}

The Hungarian Robotic MRTT Society was founded 40 years ago, and key individuals like Prof Imre Rudas set up robotic labs with special application areas, and initiated a robotics laboratory commemorating Prof. Antal Bejczy, a worldfamous (CALTEC and NASA JPL) robotics expert with Hungarian origin and long-term supporter of the Hungarian education in robotics. [IROB]. Between 2012 -2017, this excellent robotic center had published 320+ scientific papers. Several scientists and lecturers had the chance to carry out experiments and gain degrees. An excellent example of interdisciplinary topics from intelligent robotics is on Teleoperation [10], and for AI, Deep Learning a Tutorial Survey should be high-lighted [11].

AUTOMATICA, the largest European Robotic event bi-yearly in Munich, had presented a survey by statistics to prove that where robots are installed in manufacturing, more jobs are opened or created then lost. We had also learnt there the "Robotics LAW for 3D". Wherever jobs are DANGEROUS, DULL or DIFFICULT for humans, it is a European ethic, to apply robots, and never humans.

Robotic \& flexible automation research, innovation topics are envisaged on: Task-based Programming of Robots (including Cobots); Intrinsically Safe Robots; 
Soft Robots; Cognitive and Smart Robots; Mobile Manipulators for Logistics; Robot Swarms; Drones for Manufacturing; Robot Machine Tools; Shared Autonomy in Manufacturing - Cobots - Cooperative Manipulation; Robot Skill Acquisition; Augmenting the Human; Reference Architectures, Digital Twins, Trust \& Security, Navigation; Applications in Health Care, in Agriculture, in Construction. G. Z. Yang et al. [12] identified 10 grand challenges in Robotics that could have major impact in the next 5 to 10 years.

Those are: New Materials and Fabrication Schemes; Bioinspired and Bio-Hybrid Robots; Power and Energy; Robot Swarms; Navigation and Exploration; AI for Robotics; Brain-Computer Interfaces; Social Interaction; Robot Ethics and Security.

In the following section each topic is addressed in the light of Industrial Robotics.

\subsubsection{New Materials and Fabrication Schemes}

This area is touched by Soft Robotics and new fabrication methods including integrated sensors for adaptive control. Unfortunately, the mass production of the latter is still not solved.

\subsubsection{Bioinspired and Bio-Hybrid Robots}

As already mentioned Soft Robotics is one of the focus fields in robotics which includes designs from nature. Festo [13] is one of the pioneers in this topic who successfully developed Bioinspired Grippers and Manipulators for the industry. However, the spread of these products on the market is another question.

\subsubsection{Power and Energy}

While AGVs are becoming a part of everyday life in shop floors, Energy storage is meant to be a major bottleneck for mobile robotics. We are still looking forward to fundamental changes in the battery technology to reduce energy consumption to a sustainable level.

\subsubsection{Robot Swarms}

Flexible Robotics is an R\&D topic for several years and the results are manifested in Lightweight Robot Control Enhancements. Mobile platforms with Lightweight Robot Arms are just now becoming a trend in the industry, but using them in small swarms is still a new research field. 


\subsubsection{Navigation and Exploration}

Typical Use Cases for Robots is exploring places where human presence is dangerous like disaster zones, the deep sea or the space.

Industrial environments might change during production but those changes can be planned and digitally documented or traced by current sensors.

\subsubsection{AI for Robotics}

$\mathrm{AI}$ is indeed a revolutionary key to put Manufacturing Automation on a new path, including deep learning and model-based reasoning.

Current steps in the financing of AI \& Robotics show that it is an important research field across the Globe. European investigations from two associations Big Data Value Association (BDVA) and European Robotics Association (euRobotics) - are manifested in the Joint Vision Paper for an Artificial Intelligence Public Private Partnership [14]. "The Vision of the AI Public Private Partnership is to boost European industrial competitiveness and lead the world in developing and deploying value-driven trustworthy AI based on European fundamental rights, principles and values."[14]

\subsubsection{Brain-Computer Interfaces (BCIs)}

Developments to interact directly - through our brain - with the control of actuators seem to be essential in robotic prosthetics. Some people think that BCIs are needed to compete or at least have a chance against AI in the future. However, it might be a dangerous field to mix human brain activity with Artificial Intelligence.

\subsubsection{Social Interaction}

At first it may seem that Social Interaction is only a topic for Social Robotics, but it could be important also for Collaborative Robotics use cases. Some AGVs at shop floor level are already equipped with visual communication possibilities [15] to interact with humans (beam their trajectory on the floor).

\subsubsection{Medical Robotics}

To use Industrial Robots in the rehabilitation process and help stroke patients when restoring human activities of daily living is quite new. Some repetitive movements in the rehabilitation process can be tiring for the specialists, so there is a need for robotization. E.g. in a bilateral research project a robot therapeutic system has been clinically tested on 20 spastic hemiparetic post-stroke subjects [16]. Maybe some other medical fields can be covered with Cobots too, where special medical robots can be substituted. 


\subsubsection{Robot Ethics and Security}

In the Manufacturing Industry the topic "Robotics and Ethics" is only engaged in when a robot-based vision system is integrated with an AI system. In terms of Security the challenges are more general and according to G. Z. Yang et al. [12] can be divided into two groups by looking at the IT infrastructure.

The first is "escalation" where Robotics and AI might refine strategies and launch more aggressive counter operations.

The second is "lack of control". "Pervasive distribution, multiple interactions, and fast-paced execution will make control of AI systems progressively less effective while increasing the risks for unforeseen consequences and errors." [12]

\subsection{Biological Transformation of Products, Processes}

The bio-transformation can be discussed in 3 layers:

- Bio-inspired manufacturing, "INSPIRATION";

- -Bio-integrated manufacturing "INTEGRATION"; and

- -Bio-intelligent manufacturing INTERACTION layer.

Biological transformation, [17], [18] and [9] shows that value in bio-intelligence will be either decentralized or personalized, or both. It will happen by seamless fusion among ICT, bio-, AI, robotics, etc. technologies or techniques. Selected research priorities are [19]: Bio-inspired structures, sensors, actuators, additive manufacture of bio-based materials, enzymatic processes, micro-bioreactors, smart bio-manufacturing devices, bio-packaging, ecology-based manufacturing, bio-refineries, as shown in Figure 4.

By the valuable "Industry 4.0" processes in getting the industry digitized, the acquisition and generating plus the storing of data and production-related information in huge data-centers and clouds can easily be obtained.

The studying of the living environment brings us closer to understand our environment and ecosystem. [20], [21], [22]. By understanding the processes, we might be able to influence and make production technology more efficient. The German Ministry had realized early the potentials of the biological transformation, and initiated a country-wide BIO-TRAIN [19] project to see a clear picture of challenges and opportunities, as Fig. 4 and Fig. 5 explain. 


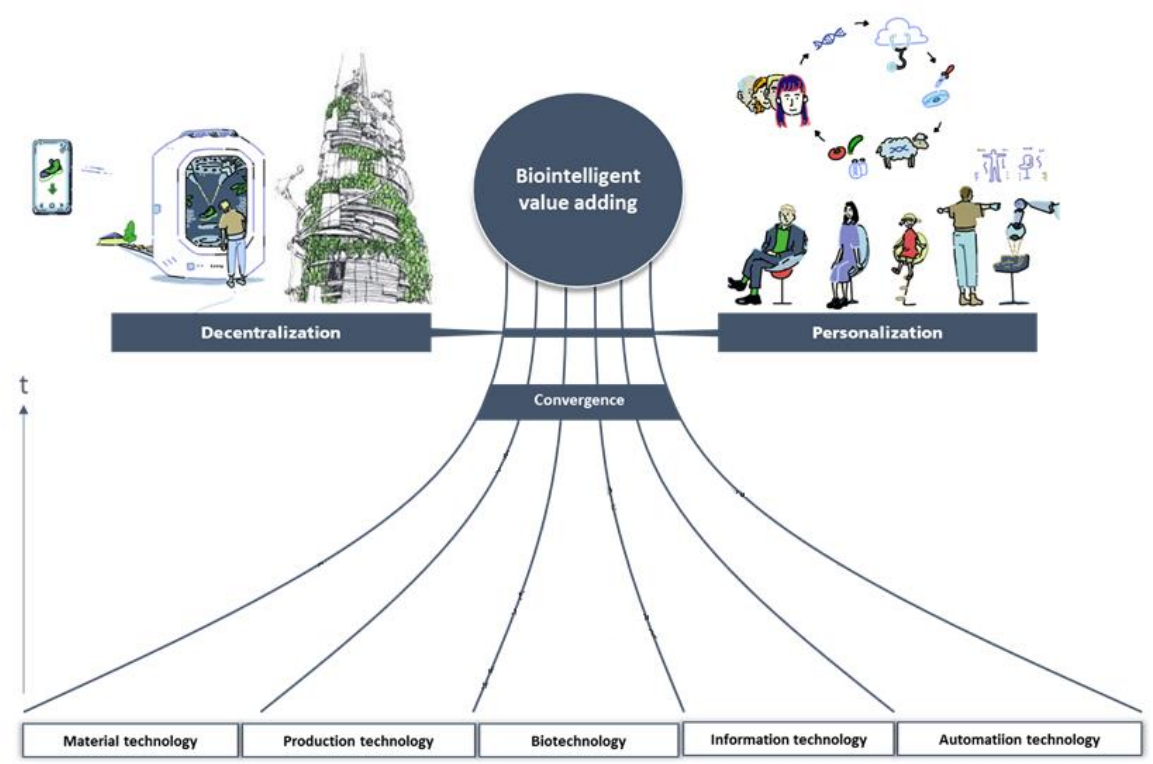

Figure 4

Integration process for Bio-transformation of products, processes @IPA

\section{Different aspects of the Biological Transformation}

\begin{tabular}{|l|l|l|l|}
\hline & Materials & Structures & Processes \\
\hline Substitution & $\begin{array}{l}\text { Fuels and chemicals from } \\
\text { Wood-waste and straw } \\
\text { Isobutene production } \\
\text { without fossil fuels }\end{array}$ & $\begin{array}{l}\text { Metallic foam } \\
\text { Highly porous } \\
\text { lightweight material } \\
\text { modeled after bones }\end{array}$ & $\begin{array}{l}\text { Bio-based plastics } \\
\text { plastics, additives and } \\
\text { compounds with } \\
\text { optimal recyclability }\end{array}$ \\
\hline Adaption & $\begin{array}{l}\text { Biomanufacturing } \\
\text { of silk proteins } \\
\text { Industrial scale silk } \\
\text { protein production the lab }\end{array}$ & $\begin{array}{l}\text { Bio-inspired machines } \\
\text { Stress oriented structural } \\
\text { design with carbon } \\
\text { fibers inspired from trees }\end{array}$ & $\begin{array}{l}\text { Self healing materials } \\
\text { Transfer of the self- } \\
\text { healing properties of plants } \\
\text { to technical materials }\end{array}$ \\
\hline Abstraction & $\begin{array}{l}\text { Programmable materials } \\
\text { Targeted adaptation of } \\
\text { materials to environ- } \\
\text { mental changes }\end{array}$ & $\begin{array}{l}\text { Artificial Neural Nets } \\
\text { Neuro-inspired } \\
\text { algorithms with } \\
\text { learning capabilities }\end{array}$ & $\begin{array}{l}\text { Swarm logistics } \\
\text { Transfer of swarm- } \\
\text { intelligence to logistics } \\
\text { systems }\end{array}$ \\
\hline Fusion & $\begin{array}{l}\text { Living cells on microchips } \\
\text { Toxicity-testing with } \\
\text { living cells on physical } \\
\text { transducers }\end{array}$ & $\begin{array}{l}\text { Theranostic implants } \\
\text { Medical devices in } \\
\text { symbiosis between tech- } \\
\text { nology and organism }\end{array}$ & $\begin{array}{l}\text { Brain Computer Interfacing } \\
\text { Communication between } \\
\text { biology and technology }\end{array}$ \\
\hline
\end{tabular}

E Fraunhofer

Figure 5

Biological transformations, BIO-TRAIN [19] project CIPA 


\subsection{The Integration of Manufacturing and Food-Processing Technologies for Products and Processes}

In several EU countries, the governments have declared the food-processing industry at a high-priority level. With the promises of the low-hanging fruits, fast ROI can be realized by applying robotics and ICT solutions which have been tested and verified in other industrial (automotive) sectors.

ManuFuture SRIA 2030 has selected the following actions and topics to address in the food industry [23]:

- Developing concepts and demonstration projects on the application of advanced manufacturing systems and industry 4.0 in the food factory, particularly in food processing.

- Establishing pilot plant/living lab facilities where food industry applications of advanced manufacturing solutions, systems, mechatronics, robotics, industry 4.0 solutions can be tested.

- To develop new business models to make the access of food businesses, particularly SMEs to new machinery, equipment, manufacturing systems easier, to reduce the limitations represented by the cost of investment.

- Establishing a systematic and regular dialogue between the manufacturing and food production, processing communities to enhance better mutual understanding and joint activities.

- Developing training and education programs to enable the adoption of Industry4.0 in the food industry.

- Exploring the opportunities for fostering innovations and entrepreneurship by transdisciplinary collaborations.

- Flexible, efficient, sustainable production of customised food products at costs approaching those of mass production, to meet the diverse and rapidly changing needs of customers and consumers.

- Reduction of unnecessary costs in food processing and supplying through efficient use of resources.

- Reduction of the environmental impact of food processing and packaging.

- More reliable food safety and hygiene and more uniform food quality through better process control and more efficient detection and removal of foreign bodies and other contaminations through smart sensor systems and robotics.

- Simulation, better design and optimisation of food manufacturing and supply processes and plants using concepts such as 'digital twins'. 
- Identification of the jobs, activities and their limitations and constraints which can be automated and robotised leading to the reduction of shortage of labour force, increasing the efficiency of controls, and improved analyses of data and trends.

- More efficient maintenance, prevention of breakdowns, reduction of the down time.

\section{Summary}

The authors' aim was to salute the pioneers of robotics and mechatronics in Hungary, in correlation to the $70^{\text {th }}$ birthday of Prof. Imre Rudas, as he is one of the key fathers of Hungarian robotics. We highlighted selected episodes, where we are proud to have reached high results. Analyzing the present trends, we have referenced the VISION2030 scientific document, and have listed the presently available list of required research-innovation- topics, the SRIA. Special details were given for the future of robotics, and on the emerging prospect of digitizing the biological transformation of manufacturing. Learning from the living ecosystems of animals and plants, will mankind learn from them, how to eliminate wastes, live with reduced energy and material consumptions, care for the future for resources? It is a great task and challenge for the upcoming generation of researchers to pave the way for the manufacturing industries to serve the growing needs of humanity in healthy food and consumer product for higher living standards, while also caring for long-term ecological stability, sustainability, e.g. in a visional circular economy.

\section{Acknowledgement}

The authors declare that the VISION for European Manufacturing 2030 document is written and edited by the ManuFuture ETP HLG group members -, and this paper is just an appetizer to read the full documents. The SRIA working documents is also an open-access presentation within the ManuFurue HLG. The research in this paper was (partially) thankfully supported by the European Commission through the H2020 project EPIC (https://www.centre-epic.eu/) under grant No. 739592. This research has also been supported by the GINOP-2.3.2-152016-00002 grant on an "Industry 4.0 research and innovation centre of excellence". The research area for the futures, like the biological and robotic areas are acknowledged to be offered by IPA experts listed in the references, but additionally being supported by key scientists Prof. Dr. Ing. Thomas Bauernhansel, head of IPA, Dr. Marion Früchtl, Dr. Günther Hörcher, Dr. Ing. Robert Miehe, members of the HLG of ManuFuture ETP. 


\section{References}

[1] G. Haidegger, Evolution of technology and users' requirements of factory communication systems from the $3^{\text {rd }}$ to the $4^{\text {th }}$ Industrial Revolution. In: IEEE $2^{\text {nd }}$ International Conference on Telecommunication and Networks, TEL-NET 2017. Noida (Uttar Pradesh), India, 2017.08.10-11. IEEE, 2017, pp. 1-6

[2] ETP; https://ec.europa.eu/research/innovation-union/index.cfm?pg=etp, last visited: 21.10 .2019

[3] ManuFuture ETP; http://www.manufuture.org/, last visited: 21.10.2019

[4] GTE; http://www.gteportal.eu, last visited: 21.10.2019

[5] Paniti I. Adaptation of Incremental Sheet Forming into cloud manufacturing. CIRP Journal of Manufacturing Science and Technology. 2014 Jan 1;7(3):185-90

[6] EFFRA, European Factories of the Future Research Association; https://www.effra.eu/, last visited: 21.10.2019

[7] HLG: MANUFUTURE -VISION 2030, consultation version, Competitive, sustainable and resilient European manufacturing, Digital ISBN:978-98995853-7-9, December 2018

[8] Luis Carneiro, INESC TEC, ManuFuture 2030, SRIA, presentation at the HLG Meeting 18-03-2019, www.manufuture.org, last visited: 21.10.2019

[9] Günter Hörcher, Markus Bessner, Thomas Bauernhansl, IPA: SRIA, http://www.ipa.fraunhofer.de/studien, last visited: 21.10.2019

[10] L. Marton, Z. Szanto, T. Haidegger, P. Galambos, and J. Kovecses, "Internet - based Bilateral Teleoperation Using a Revised Time-Domain Passivity Controller," Acta Polytechnica Hungarica, Vol. 14. No. 8. pp. 2745, 2017

[11] Károly, Artúr István, Róbert Fullér, and Péter Galambos. "Unsupervised Clustering for Deep Learning: A tutorial survey." Acta Polytechnica Hungarica, Vol. 15, No. 8 (2018): 29-53

[12] Yang, G. Z., Bellingham, J., Dupont, P. E., Fischer, P., Floridi, L., Full, R., Jacobstein, N., Kumar, V., McNutt, M., Merrifield, R. and Nelson, B. J., 2018, The grand challenges of Science Robotics. Science Robotics, 3(14), p. 7650

[13] http://www.festo.com, last visited: 21.10.2019

[14] https://www.eu-robotics.net/cms/upload/downloads/VISION_AI-

PPP_euRobotics-BDVA-Final.pdf, last visited: 21.10.2019 
[15] Chadalavada, R. T., Andreasson, H., Krug, R., \& Lilienthal, A. (2016) Empirical evaluation of human trust in an expressive mobile robot. In RSS Workshop" Social Trust in Autonomous Robots 2016", June 19, 2016

[16] http://cosmosys.mm.bme.hu/sinhungindex.html, last visited: 21.10.2019

[17] Marion Früchtl, Biological Transformation in Manufacturing, ManuFuture HLG, Meeting Milano 08.11.2018.BIO

[18] Robert Miehe, BIOINTELLIGENT VALUE ADDING; ManuFuture HLG Jubilee Conference, Milan 2018, November 8, www.Manufuture.org, last visited: 21.10 .2019

[19] Bauernhansl, T; Brecher, C; DROSSEL, W; Gumbsch, P; HOMPEL, M; Wolperdinger, M.: Biointelligence - A New Perspective for Sustainable Industrial Value Adding - Results of the Biological Transformation Preliminary Study on the Biological Transformation of Industrial Value Adding (BIOTRAIN) (Biointelligenz - Eine neue Perspektive für nachhaltige industrielle Wertschöpfung - Ergebnisse der Voruntersuchung zur Biologischen Transformation zur Biologischen Transformation der industriellen Wertschöpfung (BIOTRAIN)). Aachen, Dortmund, Dresden, Freiburg, Stuttgart, 2019, Fraunhofer-Verlag

[20] Miehe R, Bauernhansl R, Schwarz O, Traube A, Lorenzoni A, Waltersmann L, Full J, Horbelt J, Sauer A. The biological transformation of the manufacturing industry - Envisioning biointelligent value adding. Procedia CIRP, 72, 2018, pp. 739-743

[21] Miehe, R; Full, J; Sauer, A: Biointelligence in the product and in the production (Biointelligenz im Produkt und in der Produktion). In: Rieg F: Handbook of Construction (Handbuch Konstruktion) Munich: Hanser; 2018, pp. 621-634

[22] Gerald Byrne, Dimitri Dimitrov, Laszló Monostori, et al.: Biologicalisation: Biological transformation in manufacturing, CIRP Journal of Manufacturing Science and Technology, 21 (2018), pp. 1-32

[23] José Carlos Caldeira: MANUFUTURE Visison 2030 and Strategic Research and Innovation Agenda; Competitive Cooperation in Smart Specialization on the Modernization of the Food Industry Workshop, A platform for trans-sectorial collaboration19.09.2019, Budapest University of Technology and Economics 